\title{
Tumour suppressor genes in sporadic epithelial ovarian cancer
}

\author{
Ying Liu and Trivadi S. Ganesan* \\ ICRF Molecular Oncology Laboratories, Institute of Molecular Medicine, John Radcliffe Hospital, \\ Headington, Oxford OX3 9DS, UK
}

\begin{abstract}
Ovarian cancer is the most frequent cause of death from gynaecological malignancies in the western world, and sporadic epithelial ovarian cancer is its most predominant form. The aetiology of sporadic ovarian cancer remains unknown. Genetic studies have enabled a better understanding of the evolution of tumour progression. A major focus of research has been to identify tumour suppressor genes implicated in sporadic ovarian cancer over the past decade. Several tumour suppressor genes have been identified by strategies such as positional cloning and differential expression display. Further research is warranted to understand fully their contribution to the pathogenesis of sporadic ovarian cancer.
\end{abstract}

The ovary is the seventh most common site of cancer in women, after cancer of the breast, cervix, colon/rectum, stomach, corpus uteri, and lung. Incidence rates for ovarian cancer show a wide geographic variation. The highest incidence rates are observed in north-western Europe, the USA and Canada, whereas the lowest rates are observed in Asia, Africa and Latin America (Chen et al., 1992; Lynch et al., 1993). In the USA, it was estimated that in 1999, 25200 new cases would be diagnosed with ovarian cancer and that 14500 women would die of this disease (Partridge and Barnes, 1999). In the UK, the incidence of ovarian cancer is over 5000 new cases every year and it accounts for 4275 deaths per year (Chang et al., 1994). Patients with early-stage ovarian cancer, in whom the disease is confined to one or both ovaries (stage I), have good prognoses with a 5 year survival rate $>80 \%$. The prognosis of patients with advanced disease, in whom the tumour has spread within or beyond the abdominal cavity (stage III and stage IV) have a significantly worse prognosis, with only $20 \%$ of patients surviving 5 years (Friedlander, 1998). The overall survival rate in ovarian cancer is as low as $30 \%$ as most (70-80\%) patients present with advanced disease (Pecorelli et al., 1999). Any method that enables the early detection of ovarian cancer would lead to a significant decrease in mortality.

Ovarian cancer encompasses a broad range of lesions: from localized benign tumours and tumours of borderline malignant potential, to invasive malignant adenocarcinomas. Histologically, most (85-90\%) malignant ovarian tumours are of the epithelial type, which can be further grouped into histological types as: serous cystadenocarcinoma $(42 \%)$, mucinous cystadenocarcinoma (12\%), endometrioid carcinoma (15\%), undifferentiated carcinoma (17\%) and clear cell carcinoma (6\%). Approximately $5-10 \%$ of ovarian cancer

*Correspondence

Email: ganesan@icrf.icnet.uk is hereditary. It is clear now that most hereditary ovarian carcinoma cases (breast-ovarian cancer syndrome and sitespecific ovarian cancer) occur in women with germline mutations in the BRCA1 (for 'breast cancer 1') gene (Miki et al., 1994) or the BRCA2 (for 'breast cancer 2') gene (Wooster et al., 1995). Women harbouring such mutations are at a $27-60 \%$ risk of developing this disease in their life (Ford et al., 1998). Ovarian cancer associated with the hereditary nonpolyposis colon cancer syndrome (Lynch syndrome type II) is the result of mutations in one of the four known DNA mismatch repair genes: $h M S H 2$ (chromosome $2 \mathrm{p}$ ), hMLH1 (chromosome 3p), hPMS1 (chromosome 2q) and hPMS2 (chromosome 7p) (Aaltonen and Peltomaki, 1994). It was initially anticipated that somatic mutations in BRCA1, BRCA2 and mismatch repair genes would be as important in the development of sporadic epithelial ovarian cancer as in the case of the Rb1 gene, which contributes to the tumorigenesis of both hereditary and sporadic retinoblastoma. Surprisingly, very few mutations in BRCA1 (Takahashi et al., 1995), BRCA2 (Lancaster et al., 1996) and mismatch repair genes have been identified in sporadic cases, indicating a genetic difference between hereditary and sporadic ovarian cancer.

Epithelial ovarian cancer has a clonal origin (for a review, see Shelling et al., 1995), and multiple genetic alterations must occur during the malignant transformation of a single ovarian surface epithelial cell (Godwin et al., 1992). The genes that may contribute to the tumorigenesis of sporadic ovarian cancer fall into two categories: oncogenes and tumour suppressors. Oncogenes are dominant transforming genes as their activation can be caused by an alteration in a single allele. Activation of oncogenes can occur through a variety of mechanisms such as point mutation, amplification, overexpression and translocation. The normal counterpart of oncogenes, proto-oncogenes, are involved in the control of cell proliferation and differentiation. More than 60 oncogenes have been discovered and several, such as CKRAS, CERB2, CFMS, CMYC and AKT2, have been studied 
in ovarian cancer (Godwin et al., 1997). Although oncogenes may influence ovarian cancer, little is known about how and at what level the oncogenes participate in the malignant transformation of the ovarian surface epithelium (Auersperg et al., 1998). Tumour suppressor genes, unlike oncogenes, act recessively. That is, it is the loss or inactivation of both copies of a tumour suppressor gene that remove normal constraints to cell proliferation (Fig. 1a). Proof that a gene is a tumour suppressor is usually derived from transfection experiments by introduction of its wild type to malignant cells, and analysis of colony formation with a selection marker (Haber and Harlow, 1997). The ultimate proof comes from mouse knockout experiments. Two or more different suppressor genes may be inactivated in the same tumours, and the same suppressors, like the TP53 gene, may be inactivated in different tumour types. Since tumour suppressor genes play an essential role in maintaining normal cell growth, effort has been put into isolation of tumour suppressors involved in the pathogenesis of ovarian cancer.

Positional cloning has been the main strategy applied to localization and identification of tumour suppressor genes. This strategy has been very successful as is evident from the genes identified in the past decade. The main approaches involved in this strategy are: (i) cytogenetic studies to identify chromosomal alterations in patients with cancer; (ii) DNA linkage techniques to localize genes involved in inherited predisposition to cancer; and (iii) examination for loss of heterozygosity $(\mathrm{LOH})$ or allele loss studies in sporadic tumours. In the ideal case, a region with a homozygous deletion is a hallmark for the location of a tumour suppressor gene, as both of the alleles are lost, such as in the case of the BRCA2 gene. This review focuses primarily on identified or potential tumour suppressor genes implicated in sporadic ovarian cancer.

\section{Cytogenetic changes in sporadic ovarian cancer}

Techniques applied in cytogenetics commonly include chromosome banding, microdissection and fluorescent in situ hybridization (FISH). In addition to these traditional methods, new methods have been developed to allow easier identification of genomic amplifications or deletions. Comparative genomic in situ hybridization (CGH) allows fluorescent identification of chromosome gain and loss in human cancers within a single experiment. This method does not require mitotic cells, cell culture, or prior knowledge of regions of abnormality, and can be performed with small amounts of DNA (Iwabuchi et al., 1995). For example, studies using $\mathrm{CGH}$ have revealed the number of copies of one region at 3q26, where PIK3CA (PI3-kinase) that encodes the p110alpha catalytic subunit of phosphatidylinositol 3-kinase is located, as having increased in approximately $40 \%$ of ovarian and other cancers. The association between the number of copies of PIK3CA and PI3-kinase activity makes PIK3CA a candidate oncogene, because a broad range of normal cellular functions have been associated with PI3kinase-mediated signalling. Further study has indeed proved that PIK3CA is an oncogene and plays an important role in ovarian cancer (Shayesteh et al., 1999). Spectral karyotyping $(\mathrm{SKY})$ is another FISH-related method in which all the chromosomes on a metaphase spread are hybridized in a single FISH reaction with a mixture of differentially labelled DNA from each human chromosome using a combination of five fluorochromes in different ratios (Chang and Mark, 1997). The FISH signals obtained can be integrated and transformed into a different colour for each chromosome using a fluorescent image system (Schrock et al., 1996). This method has been very successful in the diagnosis of complicated translocations in cancer cell lines (Veldman et al., 1997).

Cytogenetic analysis of ovarian carcinomas indicates that karyotypes in this disease are often very complex. A wide range of numerical and structural abnormalities such as highly fragmented chromosomes, quadriradials, telomeric fusion, and complexly rearranged chromosomes has been described (Heim and Mitelman, 1995). However, nonrandom chromosome changes have been reported, including deletions in the region of $6 q 15-21$ and the translocation of chromosome 6 with chromosome 14, $\mathrm{t}(6 ; 14)(\mathrm{q} 21 ; \mathrm{q} 24)$ (Wake et al., 1980). Although deletion or translocation of chromosome 6 has not been described as the sole primary change, the loss of $6 q$ remains the most common abnormality described in this tumour to date. The frequent chromosomal abnormalities in ovarian cancers are loss of genetic material in several regions, including $3 p, 6 q$, $11 p, 17 q$, and 17p13 (Mitelman, 1995), indicating that putative tumour suppressor genes residing in these regions play an important role in the pathogenesis of ovarian cancer.

\section{Allele loss studies in sporadic ovarian cancer}

The analysis for $\mathrm{LOH}$ is the common approach used for identifying tumour suppressor genes involved in the aetiology of sporadic tumours. The basis for this strategy is the 'two hit' hypothesis by which the recessively acting genes are rendered inactive (Knudson, 1993). The first hit is usually a mutation in one of the alleles of the gene, and the second hit may occur by a variety of mechanisms including mutation or deletion. Deletion appears to be the most common mechanism associated with failure to detect heterozygosity of a polymorphic marker in tumour cells, which is, by contrast, present in the individual's normal DNA at that locus, hence the $\mathrm{LOH}$ (Fig. 1b). When a series of polymorphic markers that cover sites throughout the chromosomes are used on DNA from a panel of ovarian tumours and matching normal samples, the frequency of $\mathrm{LOH}$ in the specific region of the genome is determined. Southern blot analysis to detect restriction fragment length polymorphisms (RFLPs) was used initially to evaluate $\mathrm{LOH}$, but amplification of polymorphic microsatellite repeat markers by polymerase chain reaction (PCR) has become the method of choice. Conventional autoradiographic procedures for analysing amplified microsatellites are prone to reading errors as a result of polymerase slippage. More recently, microsatellite repeat PCR products amplified by fluorescently labelled primers can be analysed on 373 
(a) Sporadic cancer

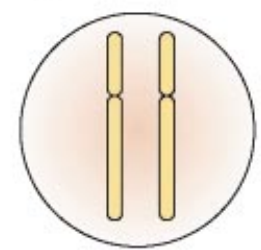

Normal cell

Hereditary cancer

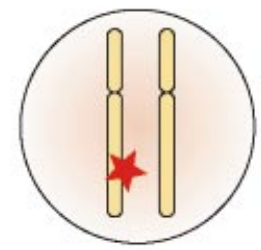

First 'hit': inherited mutation Normal cell

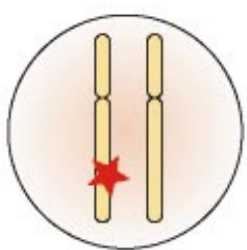

First 'hit': somatic changes (deletion of a chromosome arm or region, mutation or hypermethylation)

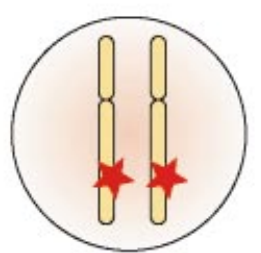

Second 'hit': somatic changes (deletion of a chromosome arm or region, mutation or hypermethylation)

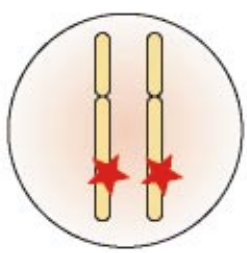

Second 'hit': somatic changes (deletion of a chromosome arm or region, mutation or hypermethylation)

(b)
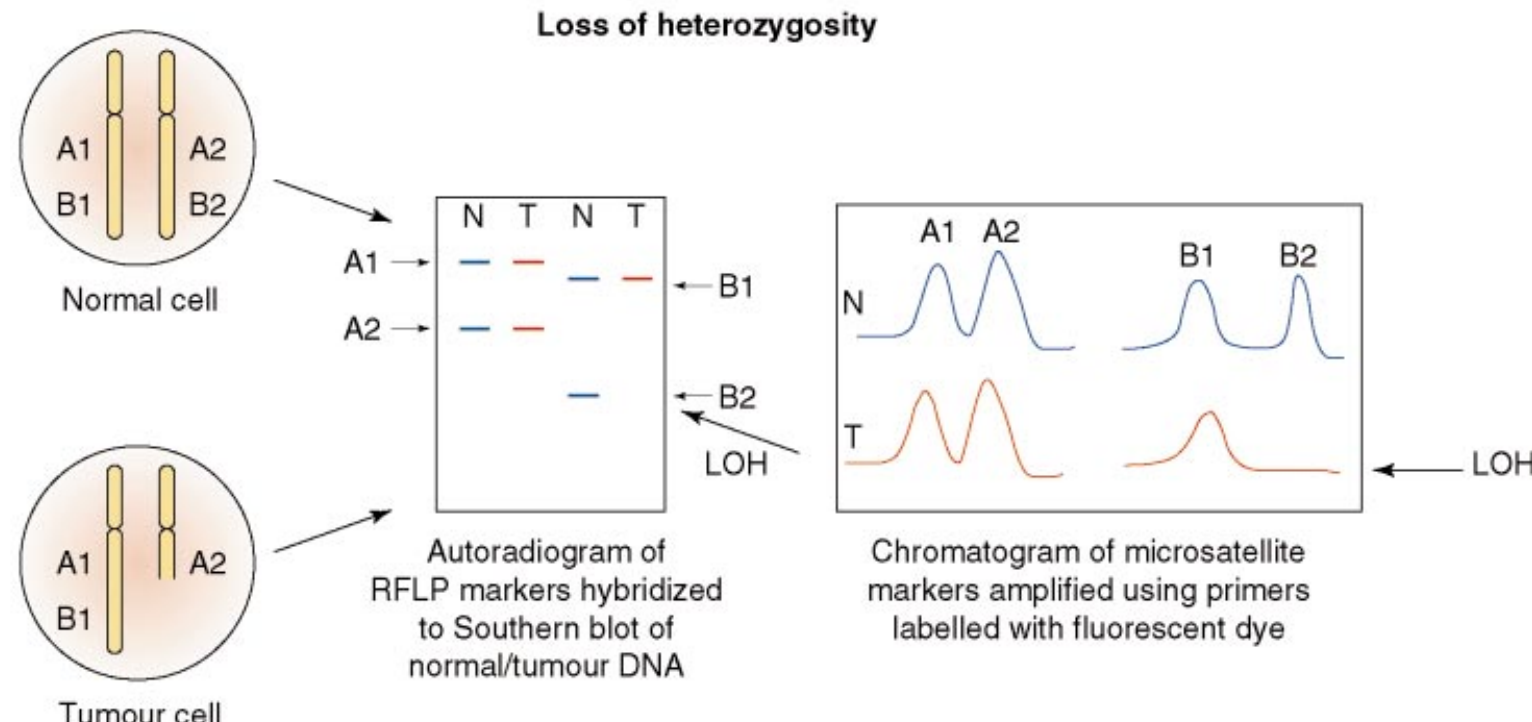

Chromatogram of microsatellite markers amplified using primers labelled with fluorescent dye

Tumour cell

Fig. 1. (a) Schematic illustration of Knudson's 'two hit' genetic model for sporadic and hereditary cancer (Knudson, 1993). (b) Schematic illustration of the principle behind analysis for loss of heterozygosity. A1/A2 and B1/B2 represent two polymorphic alleles at two different loci. Loss of one allele (B2) is demonstrated by the two techniques shown. LOH: loss of heterozygosity; RFLP: restriction fragment length polymorphism.

sequencer (PE Applied Biosystems) with the accompanying GENESCAN software. This fluorescence-based genotyping is as accurate as the standard radiolabelling technique (Schwengel et al., 1994) and has been widely applied to assess allele loss in tumours (Cooke et al., 1996).

Over 70 papers reporting $\mathrm{LOH}$ results in sporadic ovarian tumours have been published to date. However, only two of the studies (termed 'allelotype studies') have examined the $\mathrm{LOH}$ rates on all the chromosome arms in the same panel of ovarian tumours independently (Sato et al., 1991; Cliby et al., 1993). The first study examined 37 ovarian tumours with 46 polymorphic markers ( 29 were variable numbers tandem repeat markers, and the remainder were RFLP markers) and reported that chromosomal arms $4 p, 6 p, 7 p, 8 q, 12 q, 16 p$, 
$16 q, 17 p, 17 q$ and $19 q$ had LOH rates $>30 \%$ (Sato et al., 1991). Owing to the poor density of polymorphic markers on each chromosome arm and the relatively low sensitivity of the detection method (Southern analysis), the results from this study are not completely accurate. In the second allelotype study (Cliby et al., 1993), 70 polymorphic markers were tested on the same number of tumours, and PCR was used to detect microsatellite markers. In summarizing the $\mathrm{LOH}$ rates from each chromosome arm, the authors did a one-side Student's $t$ test to calculate the background rate of random chromosomal arm loss, and this was $\geqslant 35 \%$, which accounted for the high background rate of $\mathrm{LOH}$ present in the tumours studied. From this study, frequent allele losses $(>35 \%$ ) were seen in chromosomal arms $5 q, 6 q, 7 p, 8 p, 9 q$, $13 q, 14 q, 15 q, 17 p, 17 q, 18 q, 21 q$ and $22 q$.

Most LOH studies on ovarian tumours were focused on one or several chromosome arms and the results were variable, making it difficult to locate clearly a region of interest. These differences may be the result of insufficient numbers of tumours being tested, uninformative loci on the particular chromosome arm, or the varying sensitivities of the methods used. Other causes may be more significant, such as inherent genetic differences in the population studied or the differences in the tumour subtype, stage and grade. In an attempt to adjust for some of these variables, the results of chromosome arm loss from a number of $\mathrm{LOH}$ studies have been pooled (Table 1, Fig. 2). Attempts have been made to avoid duplicating data from different studies, and only results from malignant tumours have been included. Chromosomal regions where potential tumour suppressor genes have been studied are discussed in detail below.

\section{Chromosome 1}

High rates of $\mathrm{LOH}$ have been recorded on chromosomal arm 1 p (1p31 and 1p36) (Imyanitov et al., 1999; Peng et al., 2000). The $p 73$ gene, the homologue of TP53, has been isolated and mapped to $1 \mathrm{p} 36$, making it a candidate tumour suppressor gene. However, RT-PCR and western blot analyses revealed strong expression of $p 73$ in ovarian adenocarcinoma cell lines but very low or undetectable expression in normal ovarian surface epithelial cells. There was no association between $1 \mathrm{p} 36 \mathrm{LOH}$ and $p 73$ expression in ovarian tumours, nor between $p 73$ and p53 expression (Imyanitov et al., 1999). These findings indicate that $p 73$ is not the target of allele loss at 1p36. The ARHI (NOEY2) gene, located at 1p31 (Yu et al., 1999; Peng et al., 2000) is a maternally imprinted putative tumour-suppressor gene in ovarian and breast cancers with high homology to ras and rap (Yu et al., 1999) identified by differential display PCR. In most of the tumour samples with loss of heterozygosity at this region, the non-imprinted functional allele was deleted. Re-expression of $A R H I$ through transfection suppresses clonogenic growth of breast and ovarian cancer cell lines. The growth suppression was associated with downregulation of the cyclin D1 promoter activity and induction of p21 WAF1/CIP1 (Yu et al., 1999). Therefore, ARHI appears to be an imprinted tumour suppressor gene but its role in the pathogenesis of ovarian cancer remains to be determined.

\section{Chromosome 5}

The search for a tumour suppressor gene on chromosome 5 was stimulated by studies showing a high percentage loss on 5q (46\%) (Cliby et al., 1993; Allan et al., 1994; Tavassoli et al., 1996). Because the adenomatous polyposis coli ( $A P C$ ) gene is located at $5 q 21-22$, mutation analysis was performed on those tumours demonstrating $\mathrm{LOH}$. However, no mutation was detected in these samples, leading to the conclusion that another tumour suppressor gene of relevance to ovarian cancer is located on $5 q$, probably at 5q13.1-21(Tavassoli et al., 1996).

There is a relatively low frequency of $\mathrm{LOH}$ on chromosome $5 \mathrm{p}$. Nevertheless, the tumour suppressor gene Dab2/DOC2 (for 'disabled-2/differentially expressed in ovarian carcinoma $2^{\prime}$ ) was isolated independently by two groups using the differential expression display method (chromosome 5p13) (Xu et al., 1995a; Mok et al., 1998). Dab2 functions in the mitogenic signal transduction pathway and is frequently inactivated by homozygous gene deletion in tumours (Xu et al., 1998). The expression of Dab2 was absent in all ovarian carcinoma cell lines and tissues examined, but was present in normal ovarian epithelial cell lines and tissues (Mok et al., 1994). It has also been demonstrated that loss of Dab2 expression is an early event in ovarian malignancies (Fazili et al., 1999). Furthermore, when DOC-2 was transfected into the ovarian carcinoma cell line SKOV3, the stable transfectants showed significantly reduced growth rate and ability to form tumours in nude mice (Mok et al., 1998). These data indicate that downregulation of Dab2/DOC-2 may play an important role in ovarian pathogenesis.

\section{Chromosome 6}

Allele loss of up to $62 \%$ (Cooke et al., 1996) has been reported frequently (average $48 \%$; Table 1) on the long arm of chromosome 6 . The allele loss at $6 q$ was observed in all types of epithelial ovarian cancer. Three common allele loss regions at 6q21-23, 6q25 and 6q27 have been identified (for a review, see Shelling et al., 1995). Chromosomal regions at 6q14-21 (Sandhu et al., 1996) and 6q24-25 (Wan et al., 1999) suppress tumorigenicity in the ovarian cell lines.

The human homologue of the rat Lot1 gene, LOT1 (localized to 6q25) was identified through analysis of differential gene expression in normal and malignant rat ovarian surface epithelial cells. Both the human and rat ovarian carcinoma cell lines exhibited loss or decreased expression of this gene. Furthermore, upon transfection into ovarian cancer cell lines, it suppressed the growth of the cells (Abdollahi et al., 1999). LOT1 may be a novel target of growth factor signalling pathways and it may regulate the growth promoting signals as a zinc-finger motif-containing nuclear transcription factor (Abdollahi et al., 1999). 
Table 1. Allele loss in sporadic ovarian cancer

\begin{tabular}{llll}
\hline $\begin{array}{l}\text { Chromosome } \\
\text { arm }\end{array}$ & Allele loss $(\%)$ & \multicolumn{1}{c}{ Minimal allele loss region } & \multicolumn{1}{c}{ Gene(s) studied } \\
\hline $5 q$ & $41 / 114(36)$ & D 5 S424-D5S644 & APC, Dab2/DOC2 \\
$6 p$ & $60 / 171(35)$ & & \\
$6 q$ & $218 / 453(48)$ & $6 q 14-16,6 q 21-23,6 q 25-27$ & LOT1 \\
$9 p$ & $70 / 206(34)$ & $9 p 21$ & CDKN2A \\
$10 q$ & $19 / 121(16)$ & $10 q 23$ & PTEN \\
$11 p$ & $188 / 542(35)$ & $11 p 15$ & WT1, TSG101 \\
$11 q$ & $108 / 245(43)$ & $11 q 23-q$ ter & ATM \\
$13 q$ & $105 / 260(40)$ & $13 q 14,13 q 12-13$ & RB1, BRCA2 \\
$14 q$ & $67 / 188(36)$ & $14 q 12-13,14 q 32$ & TP53, OVCA1, OVCA2, HIC1 \\
$17 p$ & $407 / 667(61)$ & $17 p 13$ & NF1, BRCA1, septin \\
$17 q$ & $499 / 860(58)$ & $17 q 25$, or whole arm loss & SMAD4, DCC \\
$18 q$ & $75 / 179(42)$ & $18 q 21,18 q 23$ & LKB1 \\
$19 p$ & $53 / 181(30)$ & $19 p 13.3$ & NF2 \\
$22 q$ & $111 / 224(49)$ & $22 q 12$, D22S284-CYP2D & \\
$X p$ & $30 / 78(38)$ & Xp21.1-p11.4 & GPC3 \\
Xq & $38 / 116(34)$ & Xq11.2-12 & \\
\hline
\end{tabular}

Data summarized from: Shelling et al. (1995); Bryan et al. (1996); Cooke et al. (1996); Davis et al. (1996); Kerr et al. (1996); Phillips et al. (1996); Saito et al. (1996); Tangir et al. (1996); Tavassoli et al. (1996); Tibiletti et al. (1996, 1998); Wertheim et al. (1996); Bandera et al. (1997); Choi et al. (1997); Koike et al. (1997); Roy et al. (1997); Shih et al. (1997, 1998); Colitti et al. (1998); Edelson et al. (1998); Launonen et al. (1998); Suzuki et al. (1998, 2000); Watson et al. (1998); Brown et al. (1999); Fullwood et al. (1999); Huang et al. (1999); Imyanitov et al. (1999); Lin et al. (1999); Niederacher et al. (1999); Nishioka et al. (1999); Shridhar et al. (1999); Dion et al. (2000); Peng et al. (2000); Veugelers et al. (2000).

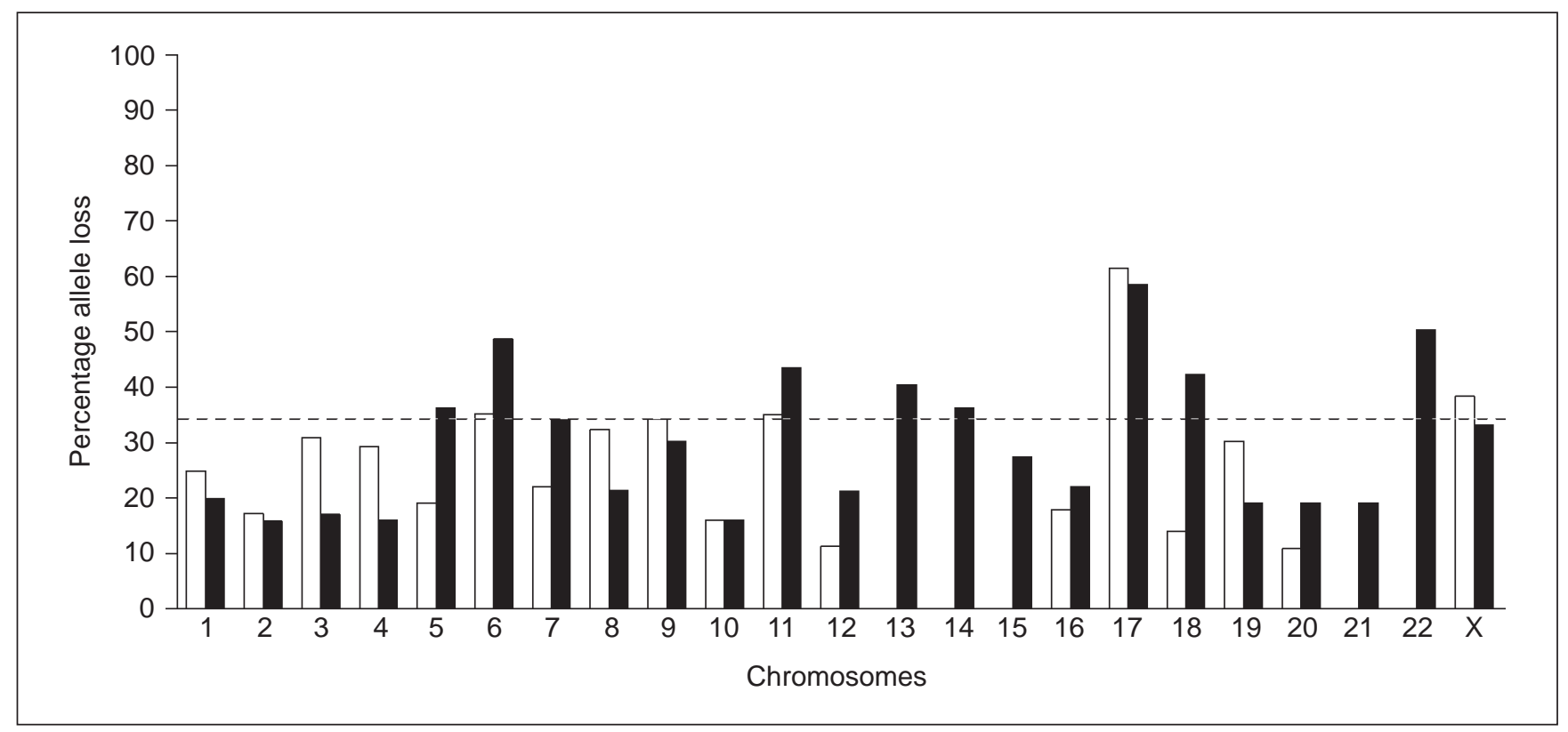

Fig. 2. Frequency of allele loss on each chromosome arm (taken as total number of markers lost in an individual chromosome arm per total number of tumours analysed). $\square$ : short (p) arm; $\mathbf{\square}$ : long (q) arm. Horizontal line indicates the average loss of heterozygosity (35\%) in all the chromosome arms analysed.

Therefore, $L O T 1$, is a putative tumour suppressor gene and further research is required to characterize this gene.

Among the several common allele loss regions on the long arm of chromosome 6, 6q27 has been reported most frequently (Saito et al., 1992, 1996; Cooke et al., 1996; Tibiletti et al., 1996, 1998; Suzuki et al., 1998). The
D6S149-D6S193 region at 6q27 was altered in all samples analysed by FISH studies using yeast artificial chromosomes (YACs) on direct metaphase spreads from fresh ovarian tumours, indicating that this change might be important even in early ovarian tumours (Tibiletti et al., 1996, 1998). The analysis of 70 malignant ovarian tumours using cosmids 
mapping to chromosomal arm $6 q$ initially defined a minimal region of allele loss between D6S149 and D6S193 (1.9 cM) in one tumour (Saito et al., 1992, 1996). Subsequent studies have shown increased frequency of allele loss on $6 q$ around the same region, although a minimal region was not defined (Wan et al., 1994; Orphanos et al., 1995). On the basis of analysis of 56 malignant ovarian tumours, the minimum region of allele loss on 6q27 is between D6S297 and D6S264 (3 cM) (Cooke et al., 1996; Chenevix-Trench et al., 1997). The maximum frequency of allele loss occurred at D6S193 (62\%) and D6S297 (52\%). Three tumours showed loss of D6S193 only, while retaining flanking markers, thus indicating that the putative tumour suppressor gene is close to D6S193. Taking into account the two previous allele loss studies, we suggest that the putative gene lies within the region between D6S264 and D6S149 (approximately $4.9 \mathrm{cM}$ ). A positional cloning approach was undertaken involving isolation of YACs, cosmids, P1-derived artificial chromosomes (PACs), bacterial artificial chromosomes (BACs) and construction of a physical and transcript map around the key polymorphic markers. Seven genes have been identified in the interval between D6S264 and D6S149 (Liu et al., 2002). Expression and mutation analysis of these genes are being carried out to identify the putative tumour suppressor gene.

\section{Chromosome 9}

The overall allele loss in chromosome $9 p$ is $34 \%$ (Table 1 ). The tumour suppressor gene CDKN2A (p16, MTS1, CDK4I mapped to $9 p$ 21), which encodes a cell cycle regulatory protein, was initially found to be homozygously deleted in gliomas (Kamb et al., 1994) or, alternatively, hypermethylated in the promoter region in some gliomas with an intact CDKN2A gene (Herman et al., 1995). Both of these events led to the loss of expression of this gene. In ovarian tumours, although $21 \%$ of tumours did not express p21, methylation deletions or mutations were not found (Shih et al., 1997).

\section{Chromosome 10}

PTEN/MMAC1 (for 'phosphatase and tensin homologue/ mutated in multiple advanced cancers') on chromosome 10 q23 is a recently identified tumour suppressor gene, which is frequently mutated in a wide range of tumours including glioma, prostate cancer, renal cancer, melanoma and endometrial cancer (Li et al., 1997). In ovarian cancer, mutations of PTEN have been found in only $20 \%$ of endometrioid type, but not in serous or mucinous types, of epithelial ovarian tumours (Obata et al., 1998). When immunohistochemistry and mutation analysis are combined, PTEN can be inactivated in other subtypes of ovarian cancer (Kurose et al., 2001).

\section{Chromosome 11}

Somatic mutations have not been identified in the coding region of the $W T 1$ (maps to 11p13) gene in a panel of ovarian tumours in which $\mathrm{LOH}$ at $11 \mathrm{p} 13$ has been observed (Bruening et al., 1993; Viel et al., 1994; Shimizu et al., 2000). A tumour suppressor gene termed TSG101 (for 'tumour susceptibility gene $101^{\prime}$ ') is located at 11p15, where 40-50\% ovarian cancers have deletions (Lu et al., 1997). In examining three ovarian cancer cell lines and 27 primary advanced stage epithelial ovarian cancers, the full length TSG101 transcript was detected in all the samples by RT-PCR and northern blot analysis.

On the long arm of chromosome 11, two regions of allele loss (11q22-23.3 and 11q23.3-24.3) have been defined by $\mathrm{LOH}$ studies. Allele loss at the $11 \mathrm{q} 23.3-24.3$ region is significantly associated with poor survival (Gabra et al., 1996). The ataxia-telangiectasia mutated (ATM) gene, which is responsible for a multisystem recessive disease ataxia-telangiectasia, is located at 11q23 (Lavin, 1999). $\mathrm{LOH}$ in the ATM gene occurred in $44 \%$ of informative cases, but no somatic alterations of the ATM gene were found in these ovarian cancer samples, including those with LOH present in the ATM gene (Koike et al., 1999). BARX2, a gene encoding a transcription factor that is homologous with the Drosophila homeobox-domain-containing proteins, was identified and mapped to $11 \mathrm{q} 25$, and shown to be a tumour suppressor gene by functional analysis (Sellar et al., 2001). However, it is unclear if $B A R X 2$ is the cause of the high $\mathrm{LOH}$ rate at $11 \mathrm{q} 23.3-24.3$.

\section{Chromosome 13}

The chromosomal arm $13 q$ shows frequent $\mathrm{LOH}$ in ovarian cancer, in particular in high grade tumours (Sato et al., 1991; Kim et al., 1994). Initially, the retinoblastoma gene (Rb1), located at 13q14, was examined and functional RB protein was shown to be present in ovarian carcinomas despite LOH at the RB locus (Dodson et al., 1994; Kim et al., 1994). BRCA2, a gene predisposing for familial breast cancer (Wooster et al., 1995), has been mapped to 13q12-13. $B R C A 2$ is rarely mutated in sporadic ovarian tumours despite the relatively high frequency of $\mathrm{LOH}$ detected in sporadic cases (Lancaster et al., 1996), indicating that a tumour suppressor gene or genes other than RB1 or BRCA2 on chromosome $13 \mathrm{q}$ must be involved in the progression of ovarian cancer.

\section{Chromosome 16}

Although the overall $\mathrm{LOH}$ rates on chromosome 16 arms are beneath the threshold of $34 \%$, a $700 \mathrm{~kb}$ region at chromosome 16q23.2 was shown to be homozygously deleted in an ovarian tumour. The WWOX (WW domain containing oxidoreductase) gene, encoding a protein with two WW domains and a short-chain dehydrogenase domain, has been mapped to this region. Homozygous deletions of WWOX exons have been reported in one ovarian cancer cell line and one primary ovarian tumour (Paige et al., 2000, 2001). 


\section{Chromosome 17}

Allele loss occurs frequently on both arms of chromosome $17(17 p, 53 \% ; 17 q, 57 \%)$ (Table 1). On the short arm, the tumour suppressor gene TP53 is located on chromosome 17p13.1 (McBride et al., 1986). Mutant p53 protein has been the most frequently encountered genetic abnormality in human malignancy (Harris and Hollstein, 1993). TP53 mutation is not a common feature of benign or borderline tumours. Furthermore, the TP53 mutation appears to be less common in localized tumours than in advanced stage tumours (Shelling et al., 1995). Patients with tumours with a mutant p53 have a poor survival rate. It remains unclear whether mutation of the TP53 gene is an independent prognostic factor, and studies with larger numbers of cases are required (Katso et al., 1997). It is possible to suppress the growth of an ovarian cancer cell line using recombinant adenovirus carrying a wild-type TP53 gene (AxCAp53) in the presence of cisplatin (Kigawa and Terakawa, 2000). Another recombinant adenovirus carrying a wild-type TP53 (Avp53) effectively suppressed the growth of peritoneal tumours in vivo in nude mice and prolonged the survival of the treated group, especially when the tumour burden was less (Kim et al., 1999).

Up to $80 \%$ (39 of 49) of allelic loss has been observed at 17p13.3 (Phillips et al., 1996). Chromosome 17p13.3 loss may precede TP53 region deletion, because allele loss was observed in early stage ovarian cancers at this region and the alterations in TP53 have been found only in advanced stages (Phillips et al., 1996; Wiper et al., 1998). Three tumour suppressor genes, HIC-1 (for 'hypermethylated in cancer'), OVCA1 and OVCA2 (for 'ovarian cancer genes' 1 and 2), have been identified in this region. HIC-1 was identified by analysis of a DNA site hypermethylated in tumour DNA (Wales et al., 1995) and is a new zinc-finger transcription factor gene that is ubiquitously expressed in normal tissues, but absent in different tumour cells, in which it is hypermethylated. The suppression of the neomycin selectability of cultured brain, breast and colon cancer cells after transfection of HIC-1 make HIC-1 a strong candidate for a tumour suppressor (Wales et al., 1995). OVCA1 and OVCA2 were identified at $17 \mathrm{p} 13.3$ by positional cloning (Schrock et al., 1996), are ubiquitously expressed and encode proteins of 443 and 227 amino acids, respectively, with no known functional motifs. Northern blot analysis revealed that OVCA1 and OVCA2 mRNA was expressed in the normal surface epithelial cells of the ovary, but that expression of this transcript was significantly reduced or was undetectable in $92 \%(11 / 12)$ of the ovarian tumours and tumour cell lines analysed (Schultz et al., 1996). Western blot analysis of extracts prepared from breast and ovarian carcinomas revealed reduced expression of OVCA1 compared with extracts from normal epithelial cells from these tissues (Bruening et al., 1999). Reduction of colony formation was also demonstrated in ovarian cancer cell lines transfected with plasmids expressing OVCA1 compared with appropriate controls. As no mutation was identified in the tumour and cell lines that have $\mathrm{LOH}$ at 17q13.3, haploinsufficiency, which was observed in the mouse gene p27/kip and the PTEN genes when they lost their tumour suppression ability, may be the mechanism silencing the gene (Di Cristofano et al., 1998; Fero et al., 1998). However, as the methylation status of OVCA1 in samples that have allele loss at $17 q 13.3$ has not been studied, the mechanism of inactivation of this gene needs further research.

On the long arm of chromosome 17, at least three distinct commonly deleted regions at $17 \mathrm{q} 12.2$ (the NF1 locus), $17 q 21$ (including the BRCA1 locus), and from $17 q 25.1$ to 17 qter have been identified in ovarian cancers. No mutation has been identified in the NF1 gene (Foulkes et al., 1994; lyengar et al., 1999) and very few mutations have been found in the BRCA1 gene in sporadic ovarian cancers (Takahashi et al., 1995). However, expression of BRCA1 may be silenced by hypermethylation in its promoter region (Mancini et al., 1998). As the region between 17q25.1 and 17 ter has a much higher frequency of $\mathrm{LOH}$ (Eccles et al., 1990; Russell et al., 1990), effort has been put into mapping this region and a human septin gene has been identified at 17q25 (Russell et al., 2000). Given that the septins are a family of genes involved in cytokinesis and cell cycle control, and that this human septin gene is expressed widely in human adult and fetal tissues (including the ovary) (Kalikin et al., 2000), the human septin gene merits further investigation as an attractive candidate tumour suppressor in sporadic ovarian cancer.

\section{Chromosome 18}

Overall, $42 \%$ of tumours showed LOH on 18q (Table 1 ). The allele loss between D18S5 and D18S11 at 18q23 was detected more frequently in stage III and IV tumours than in stage I and II tumours, implying that this allele loss may represent a late event in the progression of ovarian cancers (Chenevix-Trench et al., 1997). SMAD4 (DPC4), deleted in colorectal carcinoma, is located at $18 \mathrm{q} 21$. Allele loss was detected at the D18S46 (31\%) and D18S474 (36\%) loci, which are adjacent to the SMAD4 gene. Missense mutations were detected in 2/42 ovarian tumours and 3/8 ovarian cancers cell lines, whereas a silent mutation was detected in 1/42 primary ovarian cancers (Takakura et al., 1999).

\section{Chromosome 19}

$\mathrm{LOH}$ has been reported in about $30 \%$ of ovarian cancers on 19p13.3 (Table 1). Germline mutations in the LKB1 (STK11) gene (chromosome 19p13.3) cause characteristic hamartomas and pigmentation in patients with PeutzJeghers syndrome. Peutz-Jeghers syndrome carries an overall risk of cancer up to 20 times that of the general population. Patients with Peutz-Jeghers syndrome are also at increased risk of benign and malignant ovarian tumours, particularly granulosa cell tumours. However, like those of the BRCA1 and BRCA2 genes, LKB1 mutations can cause 


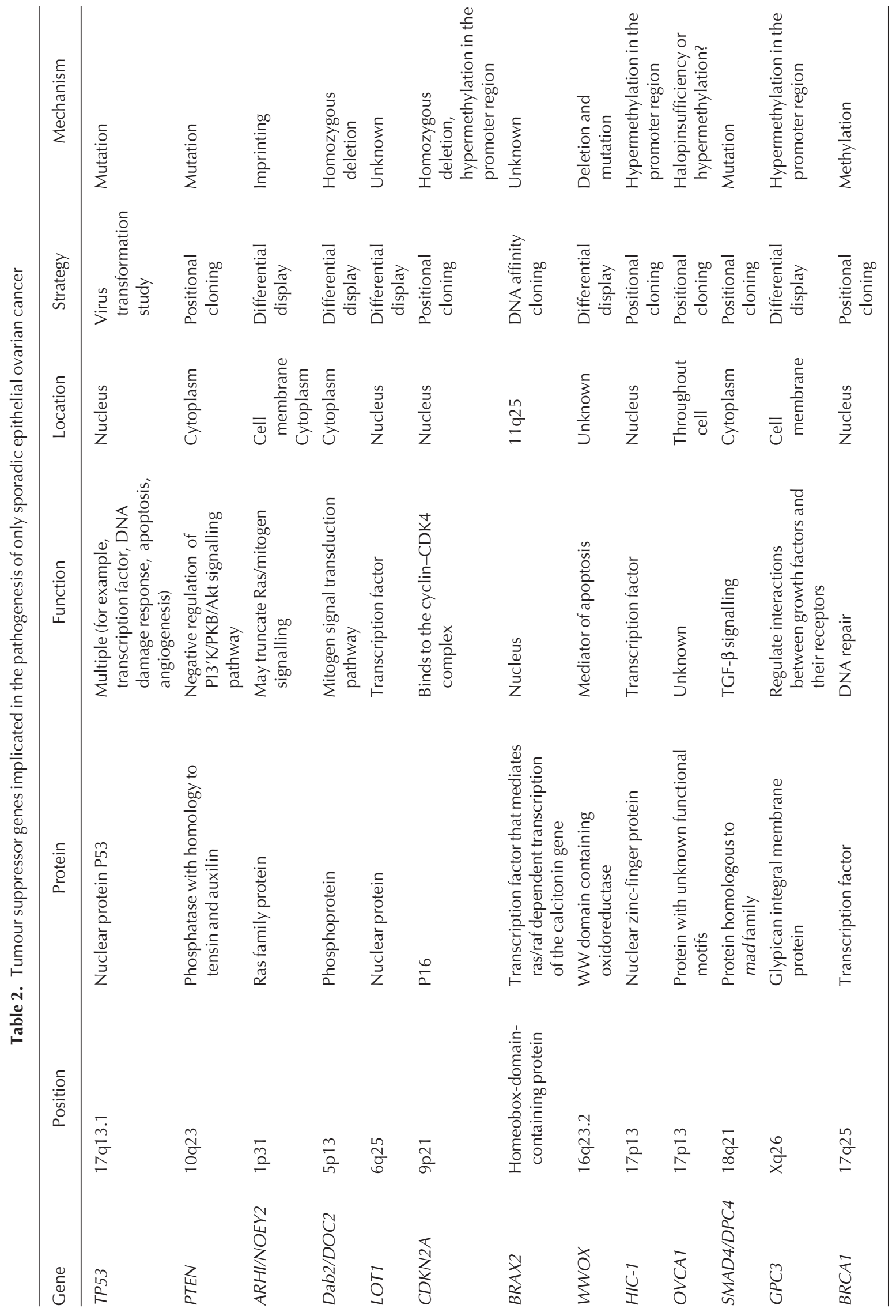


ovarian tumours when present in the germline, but occur rarely in the somatic tissue (Nishioka et al., 1999; Wang et al., 1999). Therefore, the $L K B 1$ gene may play a limited role in the development of ovarian carcinomas.

\section{Chromosome X}

High allele loss rate has been reported on both chromosomal arm Xp (38\%) and Xq (34\%) (Table 1). A region located at Xq26 (Xq11.2-12) is frequently deleted in advanced ovarian cancer (Choi et al., 1997). The GPC3 gene, located at Xq26, encodes a glypican integral membrane protein and is mutated in patients with Simpson-Golabi-Behmel syndrome (Pilia et al., 1996). No mutations were found in GPC3, but its expression was lost in four (31\%) of the cell lines analysed (Lin et al., 1999). In all of the cases in which GPC3 expression was lost, the GPC3 promoter was hypermethylated. Expression of GPC3 was restored by treatment of the cells with the demethylating agent 5-aza2 '-deoxycytidine. A colony-forming assay confirmed that ectopic GPC3 expression inhibited the growth of ovarian cancer cell lines. These results show that GPC3, a gene involved in the control of organ growth, is frequently inactivated in a subset of ovarian cancers, indicating that it may function as a tumour suppressor in the ovary.

\section{Other strategies}

The sequencing of the human genome (http://genome.cse. ucsc.edu/) is likely to accelerate the identification of important genes in the pathogenesis of cancer. One possibility is to search the database of proteins predicted from the draft human genome for paralogues of known tumour suppressor genes, although no novel genes have been identified by this method to date (Futreal et al., 2001). Another impact of the sequencing of the human genome has been the identification of 1.42 million single nucleotide polymorphisms (SNPs), which provides an average density on the available sequence of one SNP for every 1.9 kilobases (kb) (International SNP Map Working Group, 2001). With this information, a more precise analysis of $\mathrm{LOH}$ and delineation of minimal intervals of allele loss can be performed. The $\mathrm{LOH}$ status of a single gene in tumour samples can also be evaluated, as 60000 SNPs fall within exons (coding and untranslated regions) and $85 \%$ of exons are within $5 \mathrm{~kb}$ of the nearest SNP (International SNP Map Working Group, 2001). In addition, when a positional cloning investigation points to a genomic segment, any gene located in that region becomes a candidate gene. Therefore, in future, the 'positional candidate gene' approach will be the method used to identify tumour suppressor genes. The availability of the human genome sequence accelerates the determination of whether a candidate gene is mutated in sporadic ovarian tumours.

The Human Genome Project has also answered questions about genetic evolution. Only 94 of 1278 protein families in the human genome appear to be specific to vertebrates (Baltimore, 2001) and the number of genes contained in the human genome (30000-40000) is only about twice the number needed to make a fruitfly, worm or plant (Rubin, 2001). In the past decade, 50 tumour suppressor genes have been discovered in Drosophila and at least nine show clear homology to mammalian genes (Watson et al., 1994), for example, the LATS1 gene, the human homologue of lats (for 'large tumour suppressor') in Drosophila. The deletions in lats lead to over-proliferation and tumours in multiple tissues in flies (Xu et al., 1995b) and the human homologue protein Lats1 binds to the crucial cell-cycle regulator CDC2 in a cell-cycle-dependent manner (Tao et al., 1999). Furthermore, re-expression of human LATS1 in flies completely suppressed tumour growth and rescued the 'aberrant' phenotype (Tao et al., 1999). In the meantime, Lats $1^{-\digamma}$ mice were prone to softtissue sarcomas, ovarian tumours and pituitary dysfunction (St John et al., 1999). Although it has yet to be determined whether LATS1 is a human tumour suppressor gene, it is clear that the use of model organisms, even invertebrates, is a valid approach that may lead to the identification of novel human cancer genes (Kemp, 1999).

The transgenic mouse has been a very good genetic model in characterizing known genes as tumour suppressors. For example in the study of inhibin-deficient mice, both male and female inhibin-deficient mice generated by embryo stem cell (ES) technology were found to be viable, but developed sex cord stromal tumours with almost complete penetrance (Matzuk et al., 1994). However, the heterozygous mice developed normally, without any tumour formation. Since inhibins are secreted proteins, this observation is not surprising, as heterozygous cells would continue to receive the protein from the surrounding cells, thereby preventing any tumour formation. The above findings have resulted in the identification of the first secreted tumour suppressor protein. This approach can also be used to identify novel tumour suppressor genes. By deleting the region of a mouse chromosome that is syntenic to the human chromosome region with high allele loss, the tumour susceptibility of the mouse carrying the deletion can be observed (Zhang et al., 1994).

\section{Future developments}

The advances in isolating and characterizing putative tumour suppressor genes have been impressive during the past 5 years, and the current focus is on the functional analysis of the candidate genes. Besides the traditional approaches of positional cloning and knockout mouse strategies, methods such as differential expression display by means of the PCR have been successful in identifying tumour suppressors, for example the NOEY2, LOT1, Dab/DOC2 and GPC3 genes (Table 2). Nevertheless, allele loss studies have provided information about where to look for tumour suppressors. The completion of sequencing genomes in humans and other species will be of great benefit to the search for tumour suppressor genes. 
The mechanisms involved in silencing a tumour suppressor gene are mutation, deletion, rearrangement in its coding region, or hypermethylation in its promoter region. Methylation, as an 'epigenetic' gene silencing mechanism, is increasingly recognized as a common mechanism by which cancer-related genes are inactivated (Baylin et al., 1998; Jones and Laird, 1999). One example is the abnormal methylation of the promoter of the P14 ${ }^{\text {ARF }}$ gene, which results in the downregulation of the gene and the degradation of p53, disabling the p53-mediated suicide pathway (Robertson and Jones, 1998). The results of a study of melanomas showed that the Apaf- 1 gene is switched off, rather than deleted or mutated, by methylation, and can be activated again by treatment with 5 -aza- $2^{\prime}$-deoxycytidine (Soengas et al., 2001). This finding has clinical implications in that the search for ways to reactivate the genes subject to this epigenetic downregulation may be much more straightforward than previously thought. The mechanism of inactivation of potential tumour suppressor genes involved in sporadic ovarian cancer (Table 2) indicates that hypermethylation of the promoter region may be particularly significant in ovarian cancer.

An array of tumour suppressor genes has been implicated in sporadic ovarian cancer and the current knowledge is summarized (Table 2). With the exception of TP53 and PTEN, most of these genes have not been analysed in large numbers of ovarian tumours or cell lines, and their biochemical properties and exact role in the cause of sporadic ovarian cancer need further research. Taken as a group, the many presumed functions for the other known tumour suppressor genes support the notion that these genes control critical points in a wide range of cellular pathways that regulate proliferation, differentiation, apoptosis and response to genetic damage (Haber and Harlow, 1997) (Table 2). It is possible that delineation of the genetic and functional characteristics of tumour suppressor genes will enable us to diagnose and manage patients with ovarian cancer more precisely and effectively.

The authors acknowledge support from Wellbeing, Association of International Cancer Research and the Imperial Cancer Research Fund. They also acknowledge the chromosome 6 group at the Sanger Centre.

\section{References}

Key references are identified by asterisks.

Aaltonen LA and Peltomaki P (1994) Genes involved in hereditary nonpolyposis colorectal carcinoma Anticancer Research 14 1657-1660

Abdollahi A, Bao R and Hamilton TC (1999) LOT1 is a growth suppressor gene downregulated by the epidermal growth factor receptor ligands and encodes a nuclear zinc-finger protein Oncogene 18 6477-6487

Allan GJ, Cottrell S, Trowsdale J and Foulkes WD (1994) Loss of heterozygosity on chromosome 5 in sporadic ovarian carcinoma is a late event and is not associated with mutations in APC at 5q21-22 Human Mutation 3 283-291

Auersperg N, Edelson M, Mok S, Johnson S and Hamilton T (1998) The biology of ovarian cancer Seminars in Oncology 25 281-304

Baltimore D (2001) Our genome unveiled Nature 409 814-816
Bandera CA, Takahashi H, Behbakht K et al. (1997) Deletion mapping of two potential chromosome 14 tumor suppressor gene loci in ovarian carcinoma Cancer Research 57 513-515

Baylin SB, Herman JG, Graff JR, Vertino PM and Issa JP (1998) Alterations in DNA methylation: a fundamental aspect of neoplasia Advances in Cancer Research 72 141-196

Brown MR, Chuaqui R, Vocke CD, Berchuck A, Middleton LP, Emmert-Buck MR and Kohn EC (1999) Allelic loss on chromosome arm 8p: analysis of sporadic epithelial ovarian tumors Gynecologic Oncology 74 98-102

Bruening W, Gros P, Sato T, Stanimir J, Nakamura Y, Housman D and Pelletier J (1993) Analysis of the 11p13 Wilms' tumor suppressor gene (WT1) in ovarian tumors Cancer Investigation 11 393-399

Bruening W, Prowse AH, Schultz DC, Holgado-Madruga M, Wong A and Godwin AK (1999) Expression of OVCA1, a candidate tumor suppressor, is reduced in tumors and inhibits growth of ovarian cancer cells Cancer Research 59 4973-4983

Bryan EJ, Watson RH, Davis M, Hitchcock A, Foulkes WD and Campbell IG (1996) Localization of an ovarian cancer tumor suppressor gene to a 0.5 -cM region between D22S284 and CYP2D, on chromosome 22q Cancer Research $\mathbf{5 6}$ 719-721

Chang J, Bridgewater J, Gore M, Fisher C, Schofield J, Kelland and Harap K (1994) Non-surgical aspects of ovarian cancer Lancet 343 335-340

Chang SS and Mark HF (1997) Emerging molecular cytogenetic technologies Cytobios 90 7-22

Chen Y, Wu PC, Lang JH, Ge WJ, Hartge P and Brinton LA (1992) Risk factors for epithelial ovarian cancer in Beijing, China International Journal of Epidemiology 21 23-29

Chenevix-Trench G, Kerr J, Hurst T et al. (1997) Analysis of loss of heterozygosity and KRAS2 mutations in ovarian neoplasms: clinicopathological correlations Genes, Chromosomes and Cancer 18 75-83

Choi C, Cho S, Horikawa I et al. (1997) Loss of heterozygosity at chromosome segment Xq25-26.1 in advanced human ovarian carcinomas Genes, Chromosomes and Cancer $20234-242$

Cliby W, Ritland S, Hartmann L, Dodson M, Halling KC, Keeney G, Podratz KC and Jenkins RB (1993) Human epithelial ovarian cancer allelotype Cancer Research $\mathbf{5 3} 2393-2398$

Colitti CV, Rodabaugh KJ, Welch WR, Berkowitz RS and Mok SC (1998) A novel $4 \mathrm{CM}$ minimal deletion unit on chromosome 6q25.1-q25.2 associated with high grade invasive epithelial ovarian carcinomas Oncogene 16 555-559

Cooke IE, Shelling AN, Le Meuth VG, Charnock ML and Ganesan TS (1996) Allele loss on chromosome arm $6 q$ and fine mapping of the region at $6 q 27$ in epithelial ovarian cancer Genes, Chromosomes and Cancer 15 223-233

Davis M, Hitchcock A, Foulkes WD and Campbell IG (1996) Refinement of two chromosome $11 \mathrm{q}$ regions of loss of heterozygosity in ovarian cancer Cancer Research $\mathbf{5 6}$ 741-744

Di Cristofano A, Pesce B, Cordon-Cardo C and Pandolfi PP (1998) Pten is essential for embryonic development and tumour suppression Nature Genetics 19 348-355

Dion F, Mes-Masson AM, Seymour RJ, Provencher D and Tonin PN (2000) Allelotyping defines minimal imbalance at chromosomal region $17 q 25$ in non-serous epithelial ovarian cancers Oncogene 19 1466-1472

Dodson MK, Cliby WA, Xu HJ et al. (1994) Evidence of functional RB protein in epithelial ovarian carcinomas despite loss of heterozygosity at the RB locus Cancer Research 54 610-613

Eccles DM, Cranston G, Steel CM, Nakamura Y and Leonard RC (1990) Allele losses on chromosome 17 in human epithelial ovarian carcinoma Oncogene 5 1599-1601

Edelson MI, Lau CC, Colitti CV, Welch WR, Bell DA, Berkowitz RS and Mok SC (1998) A one centimorgan deletion unit on chromosome Xq12 is commonly lost in borderline and invasive epithelial ovarian tumors Oncogene 16 197-202

Fazili Z, Sun W, Mittelstaedt S, Cohen C and Xu XX (1999) Disabled-2 inactivation is an early step in ovarian tumorigenicity Oncogene $\mathbf{1 8}$ 3104-3113

Fero ML, Randel E, Gurley KE, Roberts JM and Kemp CJ (1998) The murine gene p27Kip1 is haplo-insufficient for tumour suppression Nature 396 177-180 
Ford D, Easton DF, Stratton M et al. (1998) Genetic heterogeneity and penetrance analysis of the BRCA1 and BRCA2 genes in breast cancer families. The Breast Cancer Linkage Consortium American Journal of Human Genetics 62 676-689

Foulkes WD, Englefield P and Campbell IG (1994) Mutation analysis of RASK and the 'FLR exon' of NF1 in sporadic ovarian carcinoma European Journal of Cancer 30A 528-530

Friedlander M (1998) Prognostic factors. In Ovarian Cancer 5 pp 143-152 Eds F Sharp et al. Isis Medical Media, Oxford

Fullwood P, Marchini S, Rader JS et al. (1999) Detailed genetic and physical mapping of tumor suppressor loci on chromosome $3 p$ in ovarian cancer Cancer Research 59 4662-4667

Futreal P, Kasprzyk A, Birney E, Mullikin J, Wooster R and Stratton M (2001) Cancer and genomics Nature 409 850-852

Gabra H, Watson JE, Taylor KJ, Mackay J, Leonard RC, Steel CM, Porteous DJ and Smyth JF (1996) Definition and refinement of a region of loss of heterozygosity at 11q23.3-q24.3 in epithelial ovarian cancer associated with poor prognosis Cancer Research 56 950-954

Godwin AK, Testa JR, Handel LM, Liu Z, Vanderveer LA, Tracey PA and Hamilton TC (1992) Spontaneous transformation of rat ovarian surface epithelial cells: association with cytogenetic changes and implications of repeated ovulation in the etiology of ovarian cancer Journal of the National Cancer Institute 84 592-601

Godwin A, Schultz D and Hamilton T (1997) Oncogenes and tumour suppresor genes. In Principles and Practice of Gynecological Oncology pp 107-148 Eds W Hoskins et al. Lippincott, Philadelphia, PA

Haber D and Harlow E (1997) Tumour-suppressor genes: evolving definitions in the genomic age Nature Genetics 16 320-322

Harris CC and Hollstein M (1993) Clinical implications of the p53 tumorsuppressor gene New England Journal of Medicine 329 1318-1327

Heim S and Mitelman F (1995) Cancer Cytogenetics: Chromosomal and Molecular Genetic Aberrations of Tumor Cells 2nd Edn. Wiley-Liss, New York

Herman JG, Merlo A, Mao L, Lapidus RG, Issa JP, Davidson NE, Sidransky D and Baylin SB (1995) Inactivation of the CDKN2/p16/MTS1 gene is frequently associated with aberrant DNA methylation in all common human cancers Cancer Research 55 4525-4530

Huang H, Reed CP, Mordi A, Lomberk G, Wang L, Shridhar V, Hartmann L, Jenkins R and Smith DI (1999) Frequent deletions within FRA7G at 7 q31.2 in invasive epithelial ovarian cancer Genes, Chromosomes and Cancer 24 48-55

Imyanitov EN, Birrell GW, Filippovich I et al. (1999) Frequent loss of heterozygosity at $1 \mathrm{p} 36$ in ovarian adenocarcinomas but the gene encoding p73 is unlikely to be the target Oncogene 18 4640-4642

International SNP Map Working Group (2001) A map of human genome sequence variation containing 1.42 million single nucleotide polymorphisms Nature 409 928-933

Iwabuchi H, Sakamoto M, Sakunaga H, Ma YY, Carcangiu ML, Pinkel D, Yang-Feng TL and Gray JW (1995) Genetic analysis of benign, lowgrade, and high-grade ovarian tumors Cancer Research 55 6172-6180

lyengar TD, Ng S, Lau CC, Welch WR, Bell DA, Berkowitz RS and Mok SC (1999) Differential expression of NF1 type I and type II isoforms in sporadic borderline and invasive epithelial ovarian tumors Oncogene 18 257-262

Jones PA and Laird PW (1999) Cancer epigenetics comes of age Nature Genetics 21 163-167

Kalikin LM, Sims HL and Petty EM (2000) Genomic and expression analyses of alternatively spliced transcripts of the MLL septin-like fusion gene (MSF) that map to a 17q25 region of loss in breast and ovarian tumors Genomics 63 165-172

Kamb A, Gruis NA, Weaver-Feldhaus J et al. (1994) A cell cycle regulator potentially involved in genesis of many tumor types Science $\mathbf{2 6 4}$ 436-440

Katso RM, Manek S, O'Byrne K, Playford MP, Le Meuth V and Ganesan TS (1997) Molecular approaches to diagnosis and management of ovarian cancer Cancer and Metastasis Reviews 16 81-107

Kemp CJ (1999) You don't need a backbone to carry a tumour suppressor gene [news; comment] Nature Genetics 21 147-148

Kerr J, Leary JA, Hurst T et al. (1996) Allelic loss on chromosome $7 q$ in ovarian adenocarcinomas: two critical regions and a rearrangement of the PLANH1 locus Oncogene 13 1815-1818

Kigawa J and Terakawa N (2000) Adenovirus-mediated transfer of a p53 gene in ovarian cancer Advances in Experimental Medicine and Biology 465 207-214

Kim J, Hwang ES, Kim JS, You EH, Lee SH and Lee JH (1999) Intraperitoneal gene therapy with adenoviral-mediated p53 tumor suppressor gene for ovarian cancer model in nude mouse Cancer Gene Therapy 6 172-178

Kim TM, Benedict WF, Xu HJ et al. (1994) Loss of heterozygosity on chromosome 13 is common only in the biologically more aggressive subtypes of ovarian epithelial tumors and is associated with normal retinoblastoma gene expression Cancer Research 54 605-609

*Knudson AG (1993) Antioncogenes and human cancer Proceedings of the National Academy of Sciences USA 90 10 914-10 921

Koike M, Takeuchi S, Yokota J, Park S, Hatta Y, Miller CW, Tsuruoka N and Koeffler HP (1997) Frequent loss of heterozygosity in the region of the D7S523 locus in advanced ovarian cancer Genes, Chromosomes and Cancer 19 1-5

Koike M, Takeuchi S, Park S, Hatta Y, Yokota J, Tsuruoka N and Koeffler HP (1999) Ovarian cancer: loss of heterozygosity frequently occurs in the ATM gene, but structural alterations do not occur in this gene Oncology 56 160-163

Kurose K, Zhou XP, Araki T, Cannistra SA, Maher ER and Eng C (2001) Frequent loss of PTEN expression is linked to elevated phosphorylated Akt levels, but not associated with p27 and cyclin D1 expression, in primary epithelial ovarian carcinomas American Journal of Pathology 158 2097-2106

Lancaster JM, Wooster R, Mangion J et al. (1996) Brca2 mutations in primary breast and ovarian cancers Nature Genetics 13 238-240

Launonen V, Stenback F, Puistola U, Bloigu R, Huusko P, Kytola S, Kauppila A and Winqvist R (1998) Chromosome 11q22.3-q25 LOH in ovarian cancer: association with a more aggressive disease course and involved subregions Gynecologic Oncology 71 299-304

Lavin MF (1999) ATM: the product of the gene mutated in ataxiatelangiectasia International Journal of Biochemistry and Cell Biology $\mathbf{3 1}$ 735-740

Li J, Yen C, Liaw D et al. (1997) PTEN, a putative protein tyrosine phosphatase gene mutated in human brain, breast, and prostate cancer Science 275 1943-1947

Lin H, Huber R, Schlessinger D and Morin PJ (1999) Frequent silencing of the GPC3 gene in ovarian cancer cell lines Cancer Research 59 807-810

Liu Y, Emilion G, Mungall AJ, Dunham I, Beck S, Le Meuth-Metzinger VG, Shelling AN, Charnock FML and Ganesan TS (2002) Physical and transcript map of the region between D6S264 and D6S149 on chromosome $6 \mathrm{q} 27$, the minimal region of allele loss in sporadic epithelial ovarian cancer Oncogene 21 387-399

Lu KH, Weitzel JN, Kodali S, Welch WR, Berkowitz RS and Mok SC (1997) A novel 4-cM minimally deleted region on chromosome 11p15.1 associated with high grade nonmucinous epithelial ovarian carcinomas Cancer Research 57 387-390

Lynch HT, Watson P, Lynch JF, Conway TA and Fili M (1993) Hereditary ovarian cancer. Heterogeneity in age at onset Cancer 71 573-581

McBride OW, Merry D and Givol D (1986) The gene for human p53 cellular tumor antigen is located on chromosome 17 short arm (17p13) Proceedings of the National Academy of Sciences USA 83 130-134

Mancini DN, Rodenhiser DI, Ainsworth PJ, O'Malley FP, Singh SM, Xing W and Archer TK (1998) CpG methylation within the 5' regulatory region of the BRCA1 gene is tumor specific and includes a putative CREB binding site Oncogene 16 1161-1169

Matzuk MM, Finegold MJ, Mather JP, Krummen L, Lu H and Bradley A (1994) Development of cancer cachexia-like syndrome and adrenal tumors in inhibin-deficient mice Proceedings of the National Academy of Sciences USA 91 8817-8821

Miki Y, Swensen J, Shattuck-Eidens D et al. (1994) A strong candidate for the breast and ovarian cancer susceptibility gene BRCA1 Science $\mathbf{2 6 6}$ 66-71

Mitelman F (1995) Catalog of Chromosome Aberrations in Cancer 5th Edn. Wiley-Liss, New York

Mok SC, Wong KK, Chan RK, Lau CC, Tsao SW, Knapp RC and Berkowitz RS 
(1994) Molecular cloning of differentially expressed genes in human epithelial ovarian cancer Gynecologic Oncology 52 247-252

*Mok SC, Chan WY, Wong KK et al. (1998) DOC-2, a candidate tumor suppressor gene in human epithelial ovarian cancer Oncogene $\mathbf{1 6}$ 2381-2387

Niederacher D, Yan HY, An HX, Bender HG and Beckmann MW (1999) CDKN2A gene inactivation in epithelial sporadic ovarian cancer British Journal of Cancer 80 1920-1926

Nishioka Y, Kobayashi K, Sagae S, Sugimura M, Ishioka S, Nagata M, Terasawa K, Tokino T and Kudo R (1999) Mutational analysis of STK11 gene in ovarian carcinomas Japanese Journal of Cancer Research $\mathbf{9 0}$ 629-632

*Obata K, Morland SJ, Watson RH, Hitchcock A, Chenevix-Trench G, Thomas EJ and Campbell IG (1998) Frequent PTEN/MMAC mutations in endometrioid but not serous or mucinous epithelial ovarian tumors Cancer Research 58 2095-2097

Orphanos V, McGown G, Hey Y, Thorncroft M, Santibanez-Koref M, Russell SE, Hickey I, Atkinson RJ and Boyle JM (1995) Allelic imbalance of chromosome $6 q$ in ovarian tumours British Journal of Cancer $\mathbf{7 1}$ 666-669

Paige AJ, Taylor KJ, Stewart A, Sgouros JG, Gabra H, Sellar GC, Smyth JF, Porteous DJ and Watson JE (2000) A 700-kb physical map of a region of $16 q 23.2$ homozygously deleted in multiple cancers and spanning the common fragile site FRA16D Cancer Research 60 1690-1697

*Paige AJ, Taylor KJ, Taylor C et al. (2001) WWOX: a candidate tumor suppressor gene involved in multiple tumor types Proceedings of the National Academy of Sciences USA 98 11 417-11 422

Partridge EE and Barnes MN (1999) Epithelial ovarian cancer: prevention, diagnosis, and treatment Ca-A Cancer Journal For Clinicians 49 297-320

Pecorelli S, Benedet JL, Creasman WT and Shepherd JH (1999) FIGO staging of gynecologic cancer. 1994-1997 FIGO Committee on Gynecologic Oncology. International Federation of Gynecology and Obstetrics [comment] International Journal of Gynaecology and Obstetrics 65 243-249

Peng H, Xu F, Pershad R et al. (2000) ARHI is the center of allelic deletion on chromosome $1 \mathrm{p} 31$ in ovarian and breast cancers International Journal of Cancer 86 690-694

Phillips NJ, Ziegler MR, Radford DM, Fair KL, Steinbrueck T, Xynos FP and Donis-Keller H (1996) Allelic deletion on chromosome 17p13.3 in early ovarian cancer Cancer Research 56 606-611

Pilia G, Hughes-Benzie RM, MacKenzie A et al. (1996) Mutations in GPC3, a glypican gene, cause the Simpson-Golabi-Behmel overgrowth syndrome Nature Genetics 12 241-247

Robertson KD and Jones PA (1998) The human ARF cell cycle regulatory gene promoter is a CpG island which can be silenced by DNA methylation and downregulated by wild-type p53 Molecular and Cellular Biology 18 6457-6473

Roy WJ, Jr, Watson RH, Hitchcock A and Campbell IG (1997) Frequent loss of heterozygosity on chromosomes 7 and 9 in benign epithelial ovarian tumours Oncogene 15 2031-2035

Rubin G (2001) Comparing species Nature 409 820-821

Russell SE, Hickey GI, Lowry WS, White P and Atkinson RJ (1990) Allele loss from chromosome 17 in ovarian cancer Oncogene 5 1581-1583

Russell SE, Mcllhatton MA, Burrows JF et al. (2000) Isolation and mapping of a human septin gene to a region on chromosome $17 q$, commonly deleted in sporadic epithelial ovarian tumors Cancer Research 60 4729-4734

Saito S, Saito H, Koi S, Sagae S, Kudo R, Saito J, Noda K and Nakamura Y (1992) Fine-scale deletion mapping of the distal long arm of chromosome 6 in 70 human ovarian cancers Cancer Research 52 5815-5817

Saito S, Sirahama S, Matsushima M, Suzuki M, Sagae S, Kudo R, Saito J, Noda K and Nakamura Y (1996) Definition of a commonly deleted region in ovarian cancers to a 300-kb segment of chromosome $6 \mathrm{q} 27$ Cancer Research $\mathbf{5 6}$ 5586-5589

Sandhu AK, Kaur GP, Reddy DE, Rane NS and Athwal RS (1996) A gene on $6 q$ 14-21 restores senescence to immortal ovarian tumor cells Oncogene 12 247-252
Sato T, Saito H, Morita R, Koi S, Lee JH and Nakamura Y (1991) Allelotype of human ovarian cancer Cancer Research 51 5118-5122

Schrock E, du Manoir S, Veldman T et al. (1996) Multicolor spectral karyotyping of human chromosomes Science 273 494-497

Schultz DC, Vanderveer L, Berman DB, Hamilton TC, Wong AJ and Godwin AK (1996) Identification of two candidate tumor suppressor genes on chromosome 17p13.3 Cancer Research 56 1997-2002

Schwengel DA, Jedlicka AE, Nanthakumar EJ, Weber JL and Levitt RC (1994) Comparison of fluorescence-based semi-automated genotyping of multiple microsatellite loci with autoradiographic techniques Genomics 22 46-54

Sellar GC, Li L, Watt KP et al. (2001) BARX2 induces cadherin 6 expression and is a functional suppressor of ovarian cancer progression Cancer Research 61 6977-6981

Shayesteh L, Lu Y, Kuo WL et al. (1999) PIK3CA is implicated as an oncogene in ovarian cancer Nature Genetics 21 99-102

Shelling AN, Cooke IE and Ganesan TS (1995) The genetic analysis of ovarian cancer British Journal of Cancer 71 521-527

Shih YC, Kerr J, Liu J, Hurst T, Khoo SK, Ward B, Wainwright B and Chenevix-Trench G (1997) Rare mutations and no hypermethylation at the CDKN2A locus in epithelial ovarian tumours International Journal of Cancer 70 508-511

Shih YC, Kerr J, Hurst TG, Khoo SK, Ward BG and Chenevix-Trench G (1998) No evidence for microsatellite instability from allelotype analysis of benign and low malignant potential ovarian neoplasms Gynecologic Oncology 69 210-213

Shimizu M, Toki T, Takagi Y, Konishi I and Fujii S (2000) Immunohistochemical detection of the Wilms' tumor gene (WT1) in epithelial ovarian tumors International Journal of Gynecological Pathology 19 158-163

Shridhar V, Staub J, Huntley B, Cliby W, Jenkins R, Pass HI, Hartmann L and Smith DI (1999) A novel region of deletion on chromosome 6q23.3 spanning less than $500 \mathrm{~Kb}$ in high grade invasive epithelial ovarian cancer Oncogene 18 3913-3918

Soengas M, Capodieci P, Polsky D et al. (2001) Inactivation of the apoptosis effector Apaf-1 in malignant melanoma Nature 409 207-211

St John MA, Tao W, Fei X, Fukumoto R, Carcangiu ML, Brownstein DG, Parlow AF, McGrath J and Xu T (1999) Mice deficient of Lats1 develop soft-tissue sarcomas, ovarian tumours and pituitary dysfunction Nature Genetics 21 182-186

Suzuki M, Saito S, Saga Y, Ohwada M and Sato I (1998) Loss of heterozygosity on chromosome $6 \mathrm{q} 27$ and p53 mutations in epithelial ovarian cancer Medical Oncology 15 119-123

Suzuki M, Saito S, Saga Y, Ohwada M and Sato I (2000) Mutation of K-RAS proto-oncogene and loss of heterozygosity on $6 \mathrm{q} 27$ in serous and mucinous ovarian carcinomas Cancer Genetics and Cytogenetics 118 132-135

Takahashi H, Behbakht K, McGovern PE et al. (1995) Mutation analysis of the BRCA1 gene in ovarian cancers Cancer Research 55 2998-3002

Takakura S, Okamoto A, Saito M et al. (1999) Allelic imbalance in chromosome band 18q21 and SMAD4 mutations in ovarian cancers Genes, Chromosomes and Cancer 24 264-271

Tangir J, Muto MG, Berkowitz RS, Welch WR, Bell DA and Mok SC (1996) A $400 \mathrm{~kb}$ novel deletion unit centromeric to the BRCA1 gene in sporadic epithelial ovarian cancer Oncogene 12 735-740

Tao W, Zhang S, Turenchalk GS, Stewart RA, St John MA, Chen W and Xu T (1999) Human homologue of the Drosophila melanogaster lats tumour suppressor modulates CDC2 activity Nature Genetics 21 177-181

Tavassoli M, Steingrimsdottir H, Pierce E, Jiang X, Alagoz M, Farzaneh F and Campbell IG (1996) Loss of heterozygosity on chromosome $5 q$ in ovarian cancer is frequently accompanied by TP53 mutation and identifies a tumour suppressor gene locus at 5q13.1-21 British Journal of Cancer 74 115-119

Tibiletti MG, Bernasconi B, Furlan D et al. (1996) Early involvement of $6 c$ in surface epithelial ovarian tumors Cancer Research 56 4493-4498

Tibiletti MG, Trubia M, Ponti E et al. (1998) Physical map of the D6S149-D6S193 region on chromosome 6Q27 and its involvement in benign surface epithelial ovarian tumours Oncogene 16 1639-1642

Veldman T, Vignon C, Schrock E, Rowley JD and Ried T (1997) Hidden 
chromosome abnormalities in haematological malignancies detected by multicolour spectral karyotyping Nature Genetics 15 406-410

Veugelers M, Cat BD, Muyldermans SY et al. (2000) Mutational analysis of the GPC3/GPC4 glypican gene cluster on Xq26 in patients with Simpson-Golabi-Behmel syndrome: identification of loss-of-function mutations in the GPC3 gene Human Molecular Genetics 9 1321-1328

Viel A, Giannini F, Capozzi E, Canzonieri V, Scarabelli C, Gloghini A and Boiocchi M (1994) Molecular mechanisms possibly affecting WT1 function in human ovarian tumors International Journal of Cancer $\mathbf{5 7}$ 515-521

Wake N, Hreshchyshyn M, Piver S, Matsui S and Sandverg A (1980) Specific cytogenetic changes in ovarian cancer involving chromosomes 6 and 14 Cancer Research $\mathbf{5 0} 4512$

Wales MM, Biel MA, el Deiry W, Nelkin BD, Issa JP, Cavenee WK, Kuerbitz SJ and Baylin SB (1995) p53 activates expression of HIC-1, a new candidate tumour suppressor gene on 17p13.3 Nature Medicine 1 570-577

Wan M, Zweizig S, D'Ablaing G, Zheng J, Velicescu M and Dubeau L (1994) Three distinct regions of chromosome 6 are targets of loss of heterozygosity in human ovarian carcinomas International Journal of Oncology 5 1043-1048

Wan M, Sun T, Vyas R, Zheng J, Granada E and Dubeau L (1999) Suppression of tumorigenicity in human ovarian cancer cell lines is controlled by a 2 cM fragment in chromosomal region 6q24-q25 Oncogene 18 1545-1551

Wang ZJ, Churchman M, Campbell IG, Xu WH, Yan ZY, McCluggage WG, Foulkes WD and Tomlinson IP (1999) Allele loss and mutation screen at the Peutz-Jeghers (LKB1) locus (19p13.3) in sporadic ovarian tumours British Journal of Cancer 80 70-72

Watson KL, Justice RW and Bryant PJ (1994) Drosophila in cancer research: the first fifty tumor suppressor genes Journal of Cell Science Supplement 18 19-33

Watson RH, Neville PJ, Roy WJ, Jr, Hitchcock A and Campbell IG (1998) Loss of heterozygosity on chromosomes $7 p, 7 q, 9 p$ and $11 q$ is an early event in ovarian tumorigenesis Oncogene 17 207-212

Wertheim I, Tangir J, Muto MG, Welch WR, Berkowitz RS, Chen WY and Mok SC (1996) Loss of heterozygosity of chromosome 17 in human borderline and invasive epithelial ovarian tumors Oncogene 12 2147-2153

Wiper DW, Zanotti KM, Kennedy AW, Belinson JL and Casey G (1998) Analysis of allelic imbalance on chromosome 17p13 in stage I and stage Il epithelial ovarian cancers Gynecologic Oncology 71 77-82

Wooster R, Bignell G, Lancaster J, Swift S, Seal S, Mangion J, Collins N, Gregory S, Gumbs C and Micklem G (1995) Identification of the breast cancer susceptibility gene BRCA2 Nature 378 789-792

Xu XX, Yang W, Jackowski S and Rock CO (1995a) Cloning of a nove phosphoprotein regulated by colony-stimulating factor 1 shares a domain with the Drosophila disabled gene product Journal of Biological Chemistry 27014 184-14 191

Xu T, Wang W, Zhang S, Stewart RA and Yu W (1995b) Identifying tumor suppressors in genetic mosaics: the Drosophila lats gene encodes a putative protein kinase Development 121 1053-1063

Xu XX, Yi T, Tang B and Lambeth JD (1998) Disabled-2 (Dab2) is an SH3 domain-binding partner of Grb2 Oncogene 16 1561-1569

*Yu Y, Xu F, Peng H et al. (1999) NOEY2 (ARHI), an imprinted putative tumor suppressor gene in ovarian and breast carcinomas Proceedings of the National Academy of Sciences USA 96 214-219

Zhang H, Hasty P and Bradley A (1994) Targeting frequency for deletion vectors in embryonic stem cells Molecular and Cellular Biology 14 2404-2410 